\title{
The Motivations That Drive Me
}

I may think I have found my purpose, but whether it is a life-enhancing purpose or perhaps a destructive one, and whether I then successfully live it, depends upon the motivations that drive my choices and actions. Human beings and organizations are energy systems. Our motivations determine how this energy flows through the system and how it is channeled. Everyone in business now realizes that raising employee motivation is key to employee productivity. But we need to look at which motivations are productive.

When we have negative motivations (such as fear, greed, anger, and self-importance ("ego"), our system energy flow gets blocked and distorted, with damaging or destructive consequences. Studies show that $94 \%$ of employees and/or leaders in traditional, Newtonian organizations operate from these negative motivations. When they are driven by more positive motivations (exploration/curiosity, cooperation, selfmastery, creativity, and service), both employees and their organizations thrive, as will be illustrated by later discussions of companies that have implemented Quantum Management. Haier's RenDanHeyi “Three Self Model" includes "self-motivation," and thus working or leading with a positive motivation is important to following the model. Having positive motivations is critical to realizing our greatest human potential, and companies that have positively motivated employees will realize their own best potential. This chapter presents a scale of motivations that outlines 8 negative motivations and 8 positive ones. Reflective exercises will be

(C) The Author(s) 2022

D. Zohar, Zero Distance, https://doi.org/10.1007/978-981-16-7849-3_11 
offered to help the reader recognize the motivations from which he or she is acting, and then suggestions are made for how to move from a negative motivation to a more positive one.

Any great shift of consciousness or culture requires first that we understand both the negative consequences of staying where we are and the motivations that have put us there. Why are we here in this predicament now? Just exactly where are we starting from? And then we need to envision the future. What shift are we trying to make? What are its attractive features? And what motivations would we need to get there? This need to understand motivations and how to shift them is critical to a more contented and successful personal life and to outgrowing the crises facing today's business culture.

The study of human motivations is as old as our ability to reflect on one another's behavior. It is a primary quality of our intelligence to ask "why?", and motivations are what we describe when trying to explain our own or another's behavior. Abraham Maslow's Hierarchy of Needs was the first attempt to present an organized scale of all motivations, from the most basic to the most lofty. Maslow's scale of needs has been widely used in business ever since. He listed survival as the most basic motivation, then a need for security followed by a need to belong or to be loved. These are his "deficiency needs." For what he called "higher needs," he described self-esteem, self-actualization, and peak experience.

In the years since, Maslow's hierarchy has inspired many attempts to develop motivation theory further, with psychologists, doctors, and scientists like R.B. Cattell, Ian Marshall, David Hawkins, and Daniel Goleman publishing more elaborate lists of motivations and different scales or hierarchies. I have decided to present Marshall's scale here because it has evolved together with my own earlier work on SQ (spiritual intelligence), and this will prove essential when we come to understand how a motivational shift can happen. This scale offers a new way of systematically diagnosing the motivational and emotional foundations of where a culture or an individual is now, and then suggests how we can shift the present, negative motivational state to a more desired future one.

\section{The Scale of Motivations}

Ian Marshall was a practicing medical psychiatrist and psychotherapist, with a Jungian background and learning. His scale of motivations was derived from over forty years of clinical observation of patient behavior 
and response. As we can see, the scale pictured below draws from Maslow's Pyramid of Needs, but extends Maslow's original six motivations to sixteen, eight positive ones and eight negative ones. These are arranged in a hierarchy from -8 to +8 and have the unique property that the positive and negative legs of the scale mirror one another. Thus +3 self-mastery, mirrors and is paired with -3 craving/greed; +1 exploration mirrors and is paired with -1 self-assertion, and so on. This has great implications for how to use the chart, as I will discuss in a moment (Fig. 11.1).

As implied by the numbering, it is better to have a motive of +3 than one of -1 , but it is also better to be at -1 than at -4 . Our personal effectiveness increases, and our behavior improves or has a more positive outcome as we progress up the scale. An individual driven by fear

Fig. 11.1 The scale of Scale of Motivations

motivations

$(+8)$ Enlightenment

$(+7)$ World Soul

(+6) Higher Service

$(+5)$ Generativity

(+4) Situational Mastery

(+3) Power-Within

(+2) Gregariousness

(+1) Exploration

(0) Openness

(-1) Self-Assertion

(-2) Anger

(-3) Craving

(-4) Fear

(-5) Anguish

(-6) Apathy

(-7) Guilt \& Shame

(-8) Depersonalization 
(-4) will adopt far more reactive and defensive strategies than a counterpart who is driven by self-assertion $(-1)$. This has clear implications for how bold we will be in our actions and for risk-management in companies. Fear leads to behavior that is risk-averse, or perhaps desperate; self-assertion may lead to overconfidence or carelessness.

In fact, not just our decisions and strategies, but the even deeper cognitive processes underlying them, alter as we move up or down the chart. It is clear that motivations drive behavior, but they also drive thinking. Each motivation is a whole mindset, embracing assumptions, values, aspirations, strategies, relationships, emotions, and behavior. If I have a fearful mindset, everything looks like a threat, whereas if I am ego-driven with self-assertion, I may hugely overplay my hand. A person motivated by anger $(-2)$ will use a very different decision-making process than one who is driven by gregariousness/cooperation $(+2)$. The angry person will be preoccupied with blame and a desire for retribution, and will seek strategies that bring this about. $\mathrm{He} / \mathrm{she}$ feels set against an opponent or enemy. The cooperative person will be concerned with finding a balanced analysis of any problems and a desire for consensus. He or she sees the other as a prospective partner, and appropriate strategies will follow.

Therefore, any move up or down the scale of motivations also represents a shift of outlook and behavior. The visions, goals, and strategies I adopt will be radically different depending upon my underlying motivations, whether I am an employee or a leader. We can see from this that any growth or transformation process aimed at altering behavior (habits), attitudes, or emotions is bound to fail if it does not address the motivations at play in any situation or relationship. Shifting motivation is the only stable way to shift behavior and to ensure that both we and our companies are functioning at peak performance.

As I describe each of the motivations in turn, I do so in their positive and negative, mirrored pairs. Thus we shall move both up and down the scale simultaneously, letting each negative motivation come just after its positive equivalent. This is because the goal of all our actions should be to shift ourselves from the negative to the positive. We want, of course, our actions and decisions to have a beneficial effect for ourselves or others, and nothing good can ever come from negative motivations.

0, Neutral: The position of neutrality is not itself a motivation. It is either our starting point as infants, or our life-changing cross-over point from being driven by negative motivations to acting from more positive 
ones. It is like the neutral position in a car's clutch system, free and ready to go, but with no direction yet determined. Many of us awaken fresh in neutral each morning, before the memories, images, and emotions from the day before rush in to fill our consciousness. It is like the tabula rasa, described by the philosopher Descartes-the tablet on which nothing is yet written.

+1 , Exploration: Exploration is associated with curiosity, a sense of wonder, and an open, willing attitude to whatever life throws in our path. It is very common in young children. It reflects a desire to know our way about a scene or a situation, such as that first exploration we do when we arrive at a new tourist or residential destination. These people are in open dialogue with their environment, they look and listen and they easily engage. Exploration is a recognition that we need to know, to learn, to explore, and that it will be fulfilling to do so. It involves us in reading books, papers, and magazines-anything that will teach us more and allow us actively to engage with our environment. It makes us good students and willing, attentive employees. People driven by this motivation are usually interested in music, art, and film. They love traveling to new places and are enthusiastic to solve new problems or to meet new challenges. They like to know how things work, and they pursue knowledge and learning for their own sake. All their strategies will be bent on reaching out, on extending their skills, knowledge, or area of activity. They will be drawn to innovation because it excites them, and they will greet adverse circumstances with a "What can I make of this?" attitude. Exploration is a necessary motivation associated with the self-creation we discussed in this chapter.

-1, Self-Assertion: This motivation is associated with thoughtlessness, unbridled competitiveness, too much pride, self-centeredness, and aggression. David Hawkins comments that there is enough energy in this motivation to drive the United States Marine Corps. Like the Marines, these people are always "charging over" some hill, imposing their will and structure on the environment, "taking no prisoners." Their attitude toward learning and knowledge is manipulative. They try to assert what they already know, or they engage in learning as a means to strengthening their already entrenched position. Thus they are not open to learning things that do not further their ends. In the end, this is self-defeating.

+2, Gregariousness/Cooperation: We human beings are social animals. We need to relate to others and usually gain great nourishment from 
doing so. The bonds that we form with our fellows and culture through our gregariousness are bonds of fierce loyalty often based on shared values as well as shared goals. A gregarious person usually seeks company, preferring it to being alone. He or she likes people, and enjoys doing shared social or work-related activities with them. These people make good team members, and have a strong espirit des corps. Cooperative people are good at seeing the other's point of view, and harbor a natural respect for it even if they disagree. This makes them very good negotiators, but also good at drawing out creative ideas in others. They are good listeners.

-2, Anger: We all recognize anger in others. Angry people are usually very "cold," carefully holding their emotions in check, or very "hot," letting their anger spew all over the place. They feel bad and they blame someone or something for this. Bad things in life are someone's fault. As David Hawkins puts it, "Anger as a lifestyle is exemplified by irritable, explosive people who are oversensitive to slights and become "injustice collectors,' quarrelsome, belligerent, or litigious." I They often feel spiteful and seek strategies of revenge.

+3, Self-Mastery/Power Within who has self-mastery: We usually associate personal power with the ability to move or dominate others: "power-over." But power-over is external power. A person has it because he or she owns something, occupies some position of authority or influence, has a strong body, "is somebody." A person acting from -1 , self-assertion seeks power-over as a means of using others to make himself feel strong or important. Unless wielded from a higher motivation, most power-over usually creates winners and losers, and the conflict that results.

The only person the man or woman who has self-mastery and is motivated by power-within really seeks to have power-over is him or herself. These are people who are centered in themselves, at peace with themselves. They know whom they love and what they value and they act from this level of love and/or values. They have integrity in the strict sense that they are whole people, as well as showing behavior that is filled with integrity. They may also be rooted in their skills, or, if they are athletes, in their well-trained minds and bodies. The very pleasurable sense of "flow" when performing at our physical or mental best is the correlate of power-within.

${ }^{1}$ Ibid., p. 82. 
People who have self-mastery are trustworthy. We know where they are coming from and know that that is from a place within themselves that we can trust. They have a recognizable personal style derived from deeper commitments, and they have a strong felt-sense of their own identity. These people can be counted on to fulfill any responsibility they take on.

$-\mathbf{3}$, Craving: The Buddha said that craving is the root of all suffering. Most of the Seven Deadly Sins are sins of craving. Craving expresses itself as perpetual restlessness, a sense of never having enough, of there always being something more to want or need. Driven by a sense of inner emptiness (the exact opposite of power-within), these people constantly adopt strategies of grasping. They are greedy people, who are never satisfied. Most feel they "are owed," that someone, somewhere didn't give them what they needed or never gave them a break. They want things, but often they don't think they should have to pay for them. Their greed makes them materialistic if it is a greed for money or things and it makes them jealous if it is a hunger to be loved. Craving is of course the basis of all addictions-over-eating, gambling, alcoholism, drug-addiction, etc., and the strategies of the craving person are always the strategies of an addict: Craving people may not be trustworthy where the object of their craving is concerned, betraying anything or anyone (including themselves) that frustrates satisfaction. Because they are impulsive, they are often deeply irresponsible.

+4, Situational Mastery: The man or woman that has reached +3 , selfmastery/power-within is centered in deep personal values. But when our motivation reaches situational mastery, we find ourselves rooted in wider, interpersonal values and skills-especially those of a profession, a tradition, or a system of understanding distinctive of wider thinking or some shared vision. A master stone mason wields with his hammer all the skill and all the power of master stone masons throughout history. He draws on his craft's collective pool of wisdom and skill. A master-level executive leads with an easy air of authority and inner self-assurance. He or she has an instinct for good strategies and decisions. There is a sense of inner discipline and of "flow" in a master's behavior and decisions. At the level of situational mastery, we see the bigger picture or are in tune with a larger pattern, and thus our strategies are more complex and more long-term. We'll seek long-term objectives and constantly reframe those objectives as we take in new information. 
David Hawkins claims that very few people in our culture get above the level of situational mastery. Only $8-10 \%$ achieve it. We find among them most people who have reached the top level of their profession or craft-senior doctors, higher executives, first violin players in an orchestra, champion sportsmen, leading scientists. Winston Churchill and Franklin Delano Roosevelt were master politicians, Marie Curie was a master scientist.

-4 Fear: Fear is associated with anxiety, suspicion, a sense of being threatened or of being too vulnerable. It is the very opposite of being master of the situation. Acting from this motive, I seek always to protect or defend myself. I see others in my environment as threats or enemies. I tend to see opportunities or challenges as possible threats (because I doubt my ability to deal with them). I tend to withdraw from people (those whom I feel threaten me) or the environment, I become timid. I don't volunteer and I don't take risks. Fear isolates me from the moment and costs me my spontaneity. Hence the expression, "frozen with fear." Driven by fear, both employees and business executives become risk-averse and closed to any kind of innovation or exploration.

$$
* * *
$$

We get to a place with the next eight motivations where we begin to find the exceptional people, either the supernormal especially gifted or the subnormal especially injured or damaged. These are the realms of greatness at the one extreme and of psychiatry at the other. No more than $4 \%$ of the general population is driven by these higher or lower motives. These are the people whose personalities differ from the normal, perhaps up to the extreme of incipient madness. These include border-line manic-depressive (bipolar) individuals, or those individuals prone to but not actually in schizophrenic breakdown, who are known as schizotypal. There is a well-recognized correlation between these personality disorders and creativity. The same qualities that give rise to unusual behavior confer unusual vision or exceptionally sensitive temperament. For such personalities, the risks of great catastrophe are balanced by the chance of great genius.

+5 Generativity: Generativity is a special manifestation of creativity. It is creativity driven by love or passion. A painter loves color and his art, 
Einstein said that he loved physics, Isaac Newton felt great awe and love for the universe he wished to explore. This love or passion gives generative people a sense of playfulness about their creativity. They enjoy it and identify with it. The work is the life.

Situational masters $(+4)$ draw out the potentiality within their shared tradition. They are the leading expressers of a tradition. Generative people create new traditions, new paradigms. They love and are drawn to the unknown or the unexplored and their creative gifts allow them to give new shape to the unformed. Situational masters play "finite games." They play within the boundaries. Generative people play "infinite games." They create new boundaries. ${ }^{2}$

-5 Anguish: Hamlet's famous soliloquy, "To be or not to be, that is the question," is the cry of an anguished man. Unlike grief or mourning, which is a necessary and healthy reaction to loss, anguish arises from a sense of being lost or helpless for what to do or what to decide. It comes from a sense of blocked potential. Our generative process itself is blocked. We wring our hands and feel despair. We feel stuck, caught in the moment, with little prospect for movement. Anguish often results from incurable tragedy, like having a damaged child, being a sportsman who has lost physical agility, or being an infertile woman who had desperately wanted children. Retirement can bring it on, or immersion in a situation that we feel we can't handle. Anguished people have no strategies because their very anguish arises from the fact that they can't see any. Everything seems impossible. This is, of course, an important component of depression. But although the anguished person is suffering, they have not lost all hope, as is the case with -6 , apathy.

+6, Higher Service: Higher service is the motive that drives the servant leader, the highest and most dedicated form of leadership possible. Any great leader serves something from beyond his or her self, but the servant leader serves transpersonal values-things like excellence, goodness, justice, truth, the alleviation of suffering, the salvation or enlightenment of others. Any leader serves his fellows, his community, his country, or company, but servant leaders ultimately serve their own notion of the highest or most sacred. The best of them serve that longing in the human soul that conjures up visions and possibilities. They have a

\footnotetext{
2 See Jaqmes Carse, Finite and Infinite Games.
} 
sense of vocation, of being "called" to serve and in answering to this they find their own deepest peace, their own destiny. This is focused creativity, going beyond +5 .

Servant leaders make things happen that others have found impossible, they create new ways for human beings to relate to one another, new ways for companies to serve society, new ways for societies to $b e$. The Buddha, Moses, and Jesus were such leaders. In our own times we have had the good fortune to be served by Gandhi, Martin Luther King, Mother Teresa, Nelson Mandela, and the Dalai Lama. But there is no need for such greatness in servant leadership. Any of us can be a servant leader if we act from the motive of higher service.

-6, Apathy: If Hamlet is the man of anguish, Macbeth is the man reduced to apathy. "Tomorrow and tomorrow and tomorrow/Creeps in this petty pace from day to day,/ To the last syllable of recorded time/ And all our yesterdays have lighted fools/ The way to dusty death...[Life] is a tale/ Told by an idiot, full of sound and fury,/ Signifying nothing." Macbeth has seen all his dreams and schemes come to nothing and now he feels that he is nothing. In apathy we are overwhelmed with a sense of anomie, of having no role to play in life. Where the person of anguish suffers because he or she is no longer able to play life's game, the person of apathy can't see that there is any game to play. This is a very deep form of depression, -5 .

+7 , World-Soul: The servant leader at +6 is rooted in higher values, but their calling is to be of service in this world of daily affairs. At the next level up, +7 , world-soul, a person sees himself, others, and nature as parts of the divine made manifest. Their consciousness has become one with the collective unconscious of our species (and sometimes that of other species, or the universe itself), and when they do speak or create works of art it is as though through these utterances they hear the voice of something beyond themselves. Mozart's music was literally dictated to him from this level. He said that he merely wrote down what he heard. So, too, does Shakespeare's genius for seeing and bringing to life the disparate points of view in a complex array of human characters. "All the world's a stage, and all men and women merely players," and Shakespeare saw them from the vantage point of a celestial playwright. Most of us will never reach this mystical level of motivation but we can gain intimations of it through the great works of the geniuses who dwell there, and this is why art, music, and literature are so necessary to the human soul. 
-7, Shame/Guilt: Shame and guilt fill a person with an almost exactly opposite sense of being to that experienced by world-soul. When overcome by the motivations of -7 , I feel wholly apart from any meaningful or deeper level of reality. Indeed, I feel out of joint with "existence," feel that I have no right to be here, or that my presence in some way makes the world a worse place. I experience myself as a wound or a scar on the face of existence, and may wish to destroy myself. I simply cannot face myself, or go on living with my guilt. Suicide rates are high among people driven from this motivation, often ritual ones. The Japanese tradition of hara-kiri, results from loss of face (shame/guilt), as did the practice of disgraced Roman generals falling on their swords. Judas killed himself out of unbearable shame. People acting from this level have sometimes betrayed their own deepest ideals, and their strategies may be ones of selfdestruction-either directly through suicide or indirectly through drugs, alcoholism, or reckless behavior.

+8 , Enlightenment/Serenity: We come at this point almost to a failure of words or images. As Lao Tzu wrote at the opening of The Tao te Ching, "The way that can be expressed in words is not the eternal way." That small handful of people in human history who have reached enlightenment and written about it can only allude, or speak in metaphor. They speak commonly of the total absorption or annihilation of self in "the Absolute."

It is possible to have experienced enlightenment and then to have returned to the world. The Buddha did so, as did those who have written about their experiences. But the return to the world is as an altered person, free of all negative motivations and partially identified with the experienced sacredness of reality. T.S. Eliot's Four Quartets expresses this thought, "Below, the boar hound and the boar, Pursue their pattern as before, But reconciled among the stars." Back in the world, these people live lives of grace. They are at peace with themselves and existence. Though they may pass as quite ordinary, the ordinary is for them exalted by an inner light.

-8, Depersonalization: A person who has reached enlightenment is all inner light without physical shell. A person who has undergone depersonalization is an empty shell with no core. Here, the sense of "I" has disappeared because the ego-self has disintegrated. There is no "person" left, only random utterances and uncoordinated behavior. This is the inner 
world of the hospitalized schizophrenic or the hopelessly burnt out alcoholic or drug addict. This is as close as we get to damnation while still alive. There is no further disintegration beyond it but death itself.

\section{Finding OURSelves on the Chart:}

Most of us, most of the time, act from motivations in the center of the motivational scale, that is between +4 and -4 , and in any given relationship or situation, we can use our emotional intelligence (primarily self-awareness and emotional control) to improve things, or at least limit the damage. When I am aware that I am behaving in a destructive way, that awareness gives me the power to change my behavior, or at least to excuse myself from the situation until I am in a more positive state. But the use of a reflective exercise can greatly increase this ability to recognize the motivations at play in any real-life situation, and thus our ability to control our behavior within it.

This reflective exercise recognizes that, while the occasions may be rare, most of us at some time in our lives have experienced being affected by nearly every motivation on the chart, even the more extreme ones. By recalling past instances of this, and becoming aware during the exercise of a time when we were motivated by each of them, and what effect this had on our relationships or the situation, we can greatly increase our familiarity with the chart and our power to use it as a guide in the future. Thus during my own Quantum Management training programs, I ask participants to remember an instance in the past when they were moved by each of the eight negative motivations and then each of the eight positive motivations, to write that down, and recall the consequences of their having done so, also writing down each of these recollections. How did it affect a particular relationship? How had it made a situation worse? And then I ask them to go back to each of their negative experiences and relive it in their imaginations as they ask themselves what direction that relationship or situation would have taken had they instead been acting from the paired, positive motivation. People have found this exercise both painful and insightful, and most say going through it increased both their knowledge and control of themselves and their ability to be guided by the Scale of Motivations in future. 


\section{How We Move on the Chart}

Once we see that we are acting from a lower motivation that has negative consequences, or we are inspired by a person or culture clearly acting from higher motivations than our own, we naturally want to know how to shift our own motivations. How can I get from thinking and acting out of -4 , fear to at least -2 , anger, which is some an improvement on my situation? If I am more ambitious, how can I move from -2 , anger to +2 , cooperation? Or how can I prevent myself from being dragged down from +1 exploration to -4 , fear? In short, what are the dynamics of this scale of motivations and how does shift happen? This can be articulated in three basic principles.

Principle One: A negative person or culture cannot help another on the negative scale. Two people stuck at anger, -2 , will just spark each other off and make each other more angry. Two assertive people at -1 will get locked into a power struggle. Similarly, using a negative motivation to make a change in a situation can only result in getting to some other negative motivation.

Principle Two: A person at -3 , craving, is just canceled out by a person at +3 , power-within. Equality of opposites is not enough to change the motivations of either person. To have the power to raise another up the scale, someone must make what chess players call a "knight's move." That is, it would take someone at +4 , relational mastery, to raise a -3 to -2 or higher.

Principle Three: An individual at +4 can contain another who is coming from -3 ; but an individual who is only at +2 can be dragged down by someone who is at -3 . Thus a culture or a group higher up on the scale can raise the game for those lower down. This is the point of having priests, good teachers, master artisans, and servant leaders in society. They inspire us upward with their example or vision. But it is also the case that another person, or our company culture, can drag us down. Motivations are intimately bound up with our emotional states, and our own and others' emotions can be contagious. 


\section{Seven Steps to Using the Chart of Motivations}

- Assess where you are now. What motivation is coloring your attitude or behavior in this situation or relationship?

- How is this motivation affecting your behavior or any decisions you have to make?

- What is the outcome as a result of your motivation?

- Ask what you would have liked the outcome to be?

- What motivation might better get you there?

- Work to make the motivational shift happen.

- Reap the behavioral, relationship, and outcome changes you would prefer to have.

Open Access This chapter is licensed under the terms of the Creative Commons Attribution-NonCommercial-NoDerivatives 4.0 International License (http:// creativecommons.org/licenses/by-nc-nd/4.0/), which permits any noncommercial use, sharing, distribution and reproduction in any medium or format, as long as you give appropriate credit to the original author(s) and the source, provide a link to the Creative Commons license and indicate if you modified the licensed material. You do not have permission under this license to share adapted material derived from this chapter or parts of it.

The images or other third party material in this chapter are included in the chapter's Creative Commons license, unless indicated otherwise in a credit line to the material. If material is not included in the chapter's Creative Commons license and your intended use is not permitted by statutory regulation or exceeds the permitted use, you will need to obtain permission directly from the copyright holder.

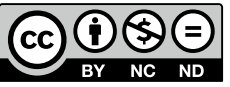

